\title{
Comparison of disinfective power according to application order of $70 \%$ isopropyl alcohol and $10 \%$ povidone-iodine
}

\author{
Sang Su Kim, Soo-Bong Yu, Joo-Duck Kim, and Sie Jeong Ryu \\ Department of Anesthesiology and Pain Medicine, Kosin University College of Medicine, Busan, Korea
}

Background: Many disinfectants have been used clinically in both single and combination applications, but there have been few studies on disinfective power according to sterilization sequence when using a combination of disinfectants. The purpose of this study was to evaluate the disinfective power of a combination of $70 \%$ isopropyl alcohol and $10 \%$ povidone-iodine (PVP-I) according to sterilization sequence.

Methods: Two hundred healthy volunteers were recruited. Subjects were disinfected with a combination of $70 \%$ isopropyl alcohol and 10\% PVP-I on both forearms, in varying sequence. The AP group included disinfections on the left forearm with isopropyl alcohol first followed by $10 \%$ PVP-I, while the PA group included disinfections on the right forearm with same disinfectants in reverse order. Skin cultures were obtained using cotton swabs 3 min after application of each disinfectant, and then were inoculated on blood agar plates for bacterial culture. Cultures were incubated at $37^{\circ} \mathrm{C}$ under aerobic conditions for 48 hours.

Results: There was no significant difference in the number of positive cultures after the $1^{\text {st }}$ disinfection (AP, 45; PA, 36, $\mathrm{P}=0.262$ ) or the $2^{\text {nd }}$ disinfection ( $\mathrm{AP}, 6 ; \mathrm{PA}, 13, \mathrm{P}=0.157$ ), suggesting that there is no relationship between disinfective power and the sequence of the disinfectants used. The number of positive cultures significantly decreased after the $2^{\text {nd }}$ disinfection $(\mathrm{P}<0.01)$, however.

Conclusions: There was no significant difference in disinfective power according to sterilization sequence with $70 \%$ isopropyl alcohol and 10\% PVP-I in healthy volunteers. The combination of 70\% isopropyl alcohol and 10\% PVP-I was more effective than disinfection with a single agent regardless of sterilization sequence. (Korean J Anesthesiol 2013; 65: 519-524)

Key Words: Colonization, Disinfectants, Isopropyl alcohol, Povidone-iodine.

\footnotetext{
Received: February 14, 2013. Revised: 1st, April 4, 2013; 2nd, May 13, 2013. Accepted: June 26, 2013.

Corresponding author: Sie Jeong Ryu, M.D., Ph.D., Department of Anesthesiology and Pain Medicine, Kosin University College of Medicine, Kosin Medical Center, Amnam-dong, Seo-gu, Busan 602-702, Korea. Tel: 82-51-990-6283, Fax: 82-51-254-2504, E-mail: siejeong@ns.kosinmed.or.kr This article is a Master's Thesis by Sang Su Kim.

(c) This is an open-access article distributed under the terms of the Creative Commons Attribution Non-Commercial License (http:// creativecommons.org/licenses/by-nc/3.0/), which permits unrestricted non-commercial use, distribution, and reproduction in any medium, provided the original work is properly cited.
} 


\section{Introduction}

Surgical and procedural site infection is a common nosocomial infection, and the importance of infection control has been highlighted by increases in the length of hospital stays and associated medical costs [1]. The absence of appropriate disinfection prior to a medical procedure-such as a surgical procedure, local or regional anesthesia, or catheter insertion-may lead to complications (cerebral meningitis, sepsis, abscess, or necrosis) due to infection and can even lead to mortality. Therefore, appropriate skin preparation is necessary for the prevention of infections [2-4]. The ideal disinfectant should have a uniform and broad-spectrum antiseptic effect on bacteria, fungi, and viruses. The disinfectant should also dramatically reduce the number of microorganisms without being harsh on skin, and it should demonstrate an immediate, sustainable, and cumulative effect [2-5]. Ethyl alcohol (ethanol), isopropyl alcohol (2-propanol), iodine tincture, and povidone-iodine (PVP-I) are generally safe and effective disinfectants [6] which can be used alone or in combination. There are many studies comparing the degree of disinfective power of a single agent to that of a combination of different agents, but few studies have explored the sequence of the disinfection procedure when disinfectants are used in combination.

This study aims to identify an effective disinfection sequence for skin preparation by comparing the effect of sterilization sequence on disinfective power when 70\% isopropyl alcohol and $10 \%$ PVP-I are used in combination.

\section{Materials and Methods}

Two hundred healthy volunteers who were categorized into class 1 or 2 of the American Society of Anesthesiologists physical status classification were included as study subjects. The study plan was approved by the Institutional Review Board, and the aim and methods of this study were explained to the study subjects before informed consent was given. The exclusion criteria for the study subjects were as follows: those who had washed forearms within 1 hour prior to the disinfectant application, had been prescribed an antibiotic in the last week, had a latex or powder allergy, were allergic to a specific disinfectant or had a skin-related allergic condition, had a localized or systemic infection, or had a wound on the hands.

Seventy percent isopropyl alcohol and 10\% PVP-I were used as disinfectants, and the left or right forearm was subjected to disinfectant application. Prior to disinfection, the subjects changed into operating gowns, and then both palms were positioned facing up while sitting on a chair. There was no specific manifestation when checking both the left and right forearms with the naked eye. The AP group had a first disinfection with
$70 \%$ isopropyl alcohol and the second disinfection with $10 \%$ PVP-I on the left forearm. The PA group, composed of the same subjects as those in the AP group, had a first disinfection with $10 \%$ PVP-I and the second disinfection with $70 \%$ isopropyl alcohol on the right forearm.

The study period was from May to July 2012, and the disinfection and test specimen collection were conducted in a recovery room within the operating room. Each disinfectant was kept at room temperature, and cotton balls were used for application of disinfectants. For the disinfection procedure and collection of test specimens, a 3-step process was followed. The first disinfectant was painted repetitively 3 times on the forearm (wrist to elbow), and 3 minutes later the test specimen was collected with a sterile cotton bud on the disinfected area. Then, the second disinfectant was applied 3 times to the same area, and the second test specimen was collected after 3 minutes using the same methods. The disinfection and specimen collection were carried out by an anesthesiology and pain specialist with 2 years or more of experience. The investigator wore a sterile surgical mask, hat, and gloves and each subject wore a disposable sterile mask to prevent contamination during the disinfection or specimen collection. The subjects were instructed not to talk, cough, or move during the procedure.

The collected test specimens were inoculated on culture media (blood agar plate, Micromedia, Busan, Korea) in three different directions and incubated for 48 hours at $37^{\circ} \mathrm{C}$ in aerobic conditions. Media with bacterial colonization, regardless of the size and number, were recorded as positive $(+)$, and the absence of bacterial colonization was recorded as negative (-). To identify isolates, some of the inoculums were collected from a bacterial colony, wet smeared on a glass slide with Gram stain, and observed under a microscope $(\times 400)$. Any specimen suspected of being contaminated during collection and incubation was excluded from the analysis.

SPSS 18.0 (SPSS Inc., Chicago, IL, USA) was used for the statistical analyses of collected data. The positive rate after the first and second disinfections in each group was compared using the McNemar test, and the number of positive cultures between the two groups was compared using the chi-square or Fisher's exact test. Statistical significance was defined as a $\mathrm{P}$ value of less than 0.05 .

\section{Results}

Eighty-eight males and 112 females were recruited as subjects, and the average age was $34.0 \pm 10.5$ years old. As the right and left forearm of the same subject were used in each respective group, other factors such as sex, age, height, and weight were not considered (Table 1). Cases in which isolates appeared after the second disinfection but not the first disinfection, cases involving 
Table 1. Demographic Data

$\begin{array}{lc}\text { Age }(\mathrm{yr}) & 34.0 \pm 10.5 \\ \text { Weight }(\mathrm{kg}) & 55.1 \pm 6.9 \\ \text { Height }(\mathrm{cm}) & 161.2 \pm 10.9 \\ \text { Sex }(\mathrm{M} / \mathrm{F}) & 88 / 112\end{array}$

Values are expressed as mean \pm SD or Number of volunteers.

Table 2. Contamination of Blood Agar Plate during Culture

\begin{tabular}{llllll}
\hline \multirow{2}{*}{\multicolumn{1}{c}{ Microorganism }} & \multicolumn{2}{c}{$\begin{array}{c}\text { AP group } \\
(\mathrm{n}=8)\end{array}$} & & \multicolumn{2}{c}{$\begin{array}{c}\text { PA group } \\
(\mathrm{n}=6)\end{array}$} \\
\cline { 2 - 3 } \cline { 5 - 6 } & $1^{\text {st }}$ & $2^{\text {nd }}$ & & $1^{\text {st }}$ & $2^{\text {nd }}$ \\
\hline Coagulase-negative staphylococci & 0 & 2 & & 0 & 2 \\
Bacillus species & 0 & 0 & & 0 & 1 \\
Streptococcus species & 0 & 1 & & 0 & 1 \\
Micrococcus species & 0 & 3 & & 0 & 0 \\
Corynebacterium species & 0 & 1 & & 0 & 0 \\
Mixed bacteria & 0 & 0 & & 1 & 0 \\
Escherichia coli & 0 & 0 & & 1 & 0 \\
Fungus & 1 & 0 & & 0 & 0
\end{tabular}

Values are number of cultured microorganisms. Contamination of blood agar plate means negative colonization after $1^{\text {st }}$ disinfection but positive colonization after $2^{\text {nd }}$ disinfection or positive colonization with non-normal flora in skin such as E.coli or positive colonization on noninnoculation area. AP group: disinfection with 70\% isopropyl alcohol first then with $10 \%$ povidone-iodine, PA group: disinfection with $10 \%$ povidone-iodine first and then with 70\% isopropyl alcohol.

incubation of isolates that were not normal flora, and cases in which isolates appeared outside the areas of inoculation in the plates were excluded from analysis due to suspected contamination; 8 and 6 such cases occurred in the AP group and PA group, respectively (Table 2 ).

Disinfective power was measured by the number of positive cultures after the disinfection. The number of positive media in the AP group ( $\mathrm{n}=192$ ), which used $70 \%$ isopropyl alcohol as the first disinfectant, was $45(23.4 \%)$. In the PA group $(\mathrm{n}=194)$, which used 10\% PVP-I, 36 (18.6\%) cultures were positive. There was no statistically significant difference observed between the two groups $(\mathrm{P}=0.262)$. The number of positive cultures collected after the second disinfection in the AP group and PA group were $6(3.1 \%)$ and $13(6.7 \%)$, respectively. No statistically significant difference was observed between the two groups ( $\mathrm{P}$ $=0.157$ ); however, both groups had significant reductions in positive media after the second disinfection compared with the result of the first disinfection $(\mathrm{P}<0.01)$ (Table 3$)$.

After the first disinfection, the number of positive cultures collected in the AP group and PA group were 45 (23.4\%) and 36 (18.6\%), respectively, and the isolates were as follows: coagulasenegative staphylococci, which occurs as a normal skin flora, was found in 34 cases and 21 cases in the AP and PA groups, respectively; in addition, there were 11 cases and 14 cases of $B a$ -
Table 3. Positive Colonization after Disinfection

\begin{tabular}{lccc}
\hline & $\begin{array}{c}\text { AP group } \\
(\mathrm{n}=192)\end{array}$ & $\begin{array}{c}\text { PA group } \\
(\mathrm{n}=194)\end{array}$ & P value \\
\hline $1^{\text {st }}$ disinfection & $45(23.4 \%)$ & $36(18.6 \%)$ & 0.262 \\
$2^{\text {nd }}$ disinfection & $6(3.1 \%)$ & $13(6.7 \%)$ & 0.157 \\
$\mathrm{P}$ value & $<0.001$ & 0.001 & \\
\hline
\end{tabular}

Values are number of positive cultured blood agar plate. There were no difference in positive colonization rate after $1^{\text {st }}$ and $2^{\text {nd }}$ disinfection between two groups. AP group: disinfection with $70 \%$ isopropyl alcohol first then with $10 \%$ povidone-iodine, PA group: disinfection with $10 \%$ povidone-iodine first and then with 70\% isopropyl alcohol.

Table 4. Classification of Microorganisms

\begin{tabular}{lrrrrr}
\hline \multirow{2}{*}{ Microorganism } & \multicolumn{2}{c}{$\begin{array}{c}\text { AP group } \\
(\mathrm{n}=192)\end{array}$} & & \multicolumn{2}{c}{$\begin{array}{c}\text { PA group } \\
(\mathrm{n}=194)\end{array}$} \\
\cline { 2 - 3 } \cline { 5 - 6 } & $1^{\text {st }}$ & $2^{\text {nd }}$ & & $1^{\text {st }}$ & $2^{\text {nd }}$ \\
\hline Coagulase-negative staphylococci & 34 & 4 & & 21 & 5 \\
Bacillus species & 11 & 2 & & 14 & 8 \\
Acinebacter baumannii & 0 & 0 & & 1 & 0
\end{tabular}

Values are number of cultured microorganisms. AP group: disinfection with $70 \%$ isopropyl alcohol first then with $10 \%$ povidone-iodine, PA group: disinfection with $10 \%$ povidone-iodine first and then with $70 \%$ isopropyl alcohol.

cillus species, and 0 cases and 1 case of Acinebacter baumannii. After the second disinfection, the numbers of positive medium responses in the in AP group and PA group were 6 and 13, respectively, and the isolates were as follows: coagulase-negative staphylococci in 4 cases and 5 cases, respectively, as well as 2 cases and 8 cases of Bacillus species (Table 4 ). There were no allergic responses observed after disinfection with $70 \%$ isopropyl alcohol. Some subjects experienced minor skin reactions with $10 \%$ PVP-I, including dry skin, pruritus, and skin flare, but these reactions disappeared after completion of the study and did not cause major discomfort.

\section{Discussion}

Infection by skin microflora can occur in the clinical practice of surgery or other procedures [7]. Disinfection is a pretreatment intended to minimize complications due to infection; although such complications are rare, disinfection is important for the prevention of infectious disease. To reduce the number of microorganisms, a thorough disinfection is needed not only of health professional's hands, but also of the surgical or procedural area. Various disinfectants are currently being used in clinical practice to prevent bacterial growth. Despite the large number of studies investigating the disinfective power of each disinfectant, the appropriateness of specific disinfectants in specific cases is not clear [8]. 
The ideal disinfectant should have rapid bactericidal activity, be able to inhibit bacterial growth, not be harmful to the patient, and not be harmful to intracellular components of the skin $[2,5]$. Generally, the primary methods of skin preparation involve the use of one, two, or more disinfectants for a set amount of time until an adequate response is achieved.

Alcohol contains a single active agent, such as ethyl alcohol or isopropyl alcohol, and demonstrates the most rapid and most effective skin preparation [9]. It also has broad-spectrum antimicrobial activity, killing gram-positive bacteria, gram-negative bacteria, yeast, fungi, and some viruses $[10,11]$. The mechanism of action for alcohol is dehydration and protein denaturation, and it disrupts the cell wall and cell membrane to release the intracellular components, eventually causing loss of cellular function [10]. Generally, 60-90\% alcohol has disinfectant properties, but anhydrous alcohol cannot denature protein as it does not contain water; hence, it has reduced disinfecting activity [11]. Rapid onset is a characteristic of alcohol, but its effects are short and unsustainable, as it also has a rapid evaporation rate. In addition, it is less effective in the presence of substances on the skin, such as blood and soil, and it dries out the skin and causes severe pain when applied to an open wound compared with PVP-I, which can be used safely and comfortably on an open wound [12]. In this study, $23.4 \%(45 / 192)$ of positive responses were seen after disinfection with 70\% isopropyl alcohol. This result is similar to previous studies' results of $12-49 \%[13,14]$. Therefore, when alcohol is used as a single agent for disinfection, a reasonable amount of bacteria should be presumed to remain active.

Iodine presents broad-spectrum antimicrobial activity against bacteria, viruses, and fungi, and it has a rapid and substantive disinfecting effect [15]. Iodine rapidly penetrates microorganisms and acts on nucleotides (DNA), fatty acids, and thiol groups. In other words, iodine inactivates protein synthesis as the thiol group becomes oxidized within cysteine, an amino acid [10]. Carrier molecules that slowly release iodine are used, as iodine irritates skin and is unstable in an aqueous or alcohol-based solution form [15]. Iodophor, which is commercially available for skin preparation and skin wounds in clinical practice, is the same as PVP-I or betadine. In PVP-I, polyvinylpyrrolidone polymer (or povidone) forms a complex with iodine [16] and acts as a reservoir for free iodine $[17,18]$. Unlike alcohol, the disinfectant effect is sustained, but iodine is released from carrier molecules and several minutes are required for the maximal antimicrobial effect [15]. In this study, the test specimens were collected 3 minutes after application, as the manufacturer recommends allowing 3-5 minutes for drying and maximum effectiveness. Because alcohol has a fast evaporation rate, its disinfection effect is not sustained, plus there are no recommendations regarding drying. Therefore, for the convenience of the study, the test specimens were collected 3 minutes after application in accordance with PVP-I usage guidelines. The incubation time of collected specimens was related to inoculum size. A large inoculum requires incubation for 24 hours and the standard inoculum size requires 48 hours [19]; hence, 48 hours was allowed for incubation in this study. The use of PVP-I requires thorough washing of blood or bodily fluids from the skin prior to application, otherwise the reaction of iodophors with blood, fat, and other proteins and minerals on the skin may reduce or neutralize the disinfection activity of the iodine-containing disinfectant [20,21]. In this study, $19.5 \%$ (36/194) of positive responses were seen after a single disinfection with $10 \%$ PVP-I, while previous studies reported a rate of $10-35 \%$ of positive responses after disinfection with povidone $[22,23]$. Therefore, as with alcohol, a reasonable number of microorganisms remained active after the use of PVP-I as a single agent. However, in this study, the combination of 70\% isopropyl alcohol and 10\% PVP-I resulted in an approximately $95 \%$ disinfection rate, a significant increase in the inhibition of microorganisms relative to that of a single agent. Thus, at least two disinfectants should be considered in cases involving a possible surgical or post-procedural infection.

The use of disinfectant solution with a combination of PVP-I and alcohol is known to have a relatively high rate of bacterial reduction compared to PVP-I as a single agent in pre-surgical disinfection [24,25]. Art [6] reported that a combination of either ethyl alcohol or isopropyl alcohol with PVP-I would have a synergistic effect, as each active ingredient has different modes of action and varied performance characteristics. Therefore, these combined agents present more rapid and more broad-spectrum antimicrobial activity, as well as a more sustained disinfectant effect, than the use of ethyl or isopropyl alcohol alone. The combination of PVP-I and alcohol resulted in a very low bacterial incidence even in this study, which signifies a high disinfective power. The present study involved a short-term comparison of the effect of disinfectants, and based on evidence that the bactericidal effects of PVP-I continue until the disappearance of color [26], disinfection with PVP-I after disinfection with isopropyl is considered favorable in cases that require sustained disinfection activity, such as for surgical wounds or catheter regions. The Infusion Nurses Society also recommended the use of combined disinfectants, with the sequence of first isopropyl and then PVPI, for the disinfection of catheter regions [27].

A recent study reported favorable results for DuraPrep (3M Health Care, St. Paul, MN, USA), a combination agent containing alcohol as a broad-spectrum antiseptic disinfectant and iodophor as a polymer complex [28]. In comparison to the use of two separate agents, the advantage of a combination product is timesaving, as it is rapid and simple, but it is inflammable due to the alcohol content and its use is limited in iodine-allergic patients.

A limitation of this study is that, apart from the antimicrobial effect of the active ingredient, the washing effect associated with 
the volume of the disinfectants used was not considered. If we had used a normal saline group as a control, then the washing effect could have been excluded from the results. In addition, $3.5 \%$ of cases were affected by contamination during test specimen collection and/or incubation; while this is similar to the contamination rates of $3-4 \%$ reported in previous studies [22,29], its effect on the results cannot be ruled out. Therefore, prevention of contamination during specimen collection and processing is considered important in increasing study reliability.

In conclusion, in healthy subjects, there was no disinfective power difference between the different sequences of $70 \%$ isopropyl alcohol and 10\% PVP-I use $(\mathrm{P}=0.157)$. However, the present study confirmed that the use of two different disinfectants for skin preparation is more effective in reducing bacterial growth than the use of a single agent, which has been reported in previous studies.

In this study, a second disinfection increased the disinfective power regardless of the disinfection sequence. Further research is warranted, however, to determine whether combination disinfection with different disinfectants has the same power as disinfection with the same disinfectant multiple times within a certain time interval.

\section{References}

1. Park ES, Kim KS, Lee WJ, Jang SY, Choi JY, Kim JM. The economical impact of surgical site infections. Korean J Nosocomial Infect Control 2005; 10: 57-64.

2. Gibson KL, Donald AW, Hariharan H, McCarville C. Comparison of two pre-surgical skin preparation techniques. Can J Vet Res 1997; 61: 154-6.

3. Bouhemad B, Dounas M, Mercier FJ, Benhamou D. Bacterial meningitis following combined spinal-epidural analgesia for labour. Anaesthesia 1998; 53: 292-5.

4. Maki DG, Ringer M, Alvarado CJ. Prospective randomized trial of povidone iodine, alcohol, and chlorhexidine for prevention of infection associated with central venous and arterial catheters. Lancet 1991; 338: 339-43.

5. Rutala WA. APIC Guidelines for selection and use of disinfectants. Am J Infect Control 1996; 24: 313-42.

6. Art G. Combination povidone-iodine and alcohol formulation more effective, more convenient versus formulations containing either iodine or alcohol alone. J Infus Nurs 2005; 28: 314-20.

7. Sato S, Sakuragi T, Dan K. Human skin flora as a potential source of epidural abscess. Anesthesiology 1996; 85: 1276-82.

8. Malani A, Trimble K, Parekh V, Chenoweth C, Kaufman S, Saint S. Review of clinical trials of skin antiseptic agents used to reduce blood culture contamination. Infect Control Hosp Epidemiol 2007; 28: 892-5.

9. Mangram AJ, Horan TC, Pearson MI, Silver LC, Jarvis WR. Guideline for prevention of surgical site infection. Infect Control Hosp Epidemiol 1999; 20: 250-78.

10. McDonnell G, Russell AD. Antiseptics and disinfectants: activity, action, and resistance. Clin Microbiol Rev 1999; 12: 147-79.

11. Jackson MM. Topical antiseptics in healthcare. Clin Lab Sci 2005; 18: 160-9.

12. Burks RI. Povidone-iodine solution in wound treatment. Phys Ther 1998; 78: 212-8.

13. McNeely JK, Trentadue NC, Rusy LM, Farber NE. Culture of bacteria from lumbar and caudal epidural catheters used for postoperative analgesia in children. Reg Anesth 1997; 22: 428-31.

14. Small H, Adams D, Casey AL, Crosby CT, Lambert PA, Elliott T. Efficacy of adding 2\% (w/v) chlorhexidine gluconate to $70 \%$ (v/v) isopropyl alcohol for skin disinfection prior to peripheral venous cannulation. Infect Control Hosp Epidemiol 2008; 29: 963-5.

15. Block SS. Disinfection, Sterilization, and Preservation. 5th ed. Philadelphia, Lea \& Febiger. 2001, pp 159-83.

16. Zamora JL. Chemical and microbiologic characteristics and toxicity of povidone-iodine solutions. Am J Surg 1986; 151: 400-6.

17. Durani P, Leaper D. Povidone-iodine: use in hand disinfection, skin preparation and antiseptic irrigation. Int Wound J 2008; 5: 376-87.

18. Sauerbrei A, Wutzler P. Virucidal efficacy of povidone-iodine- containing disinfectants. Lett Appl Microbiol 2010; 51: 158-63.

19. Nguyen MH, Yu CY. Influence of incubation time, inoculum size, and glucose concentrations on spectrophotometric endpoint determinations for amphotericin B, fluconazole, and itraconazole. J Clin Microbiol 1999; 37: 141-5.

20. Gilliam DL, Nelson CL. Comparison of a one-step iodophor skin preparation versus traditional preparation in total joint surgery. Clin Orthop Relat Res 1990; 250: 258-60.

21. Zamora JL, Price MF, Chuang P, Gentry LO. Inhibition of povidone- iodine's bactericidal activity by common organic substances: an experimental study. Surgery 1985; 98: 25-9.

22. Nahm FS, Ahn WS, Lee CJ, Ham BM. Chlorhexidine versus povidone iodine in bacterial contamination rate of needles used for spinal anesthesia. Korean J Anesthesiol 2004; 47: S1-4.

23. Darouiche RO, Wall MJ Jr, Itani KM, Otterson MF, Webb AL, Carrick MM, et al. Chlorhexidine-alcohol versus povidone-iodine for surgical-site antisepsis. N Engl J Med 2010; 362: 18-26.

24. Arata T, Murakami T, Hiraj Y. Evaluation of povidone iodine alcoholic solution for operative disinfection. Postgrad Med J 1993; 69(Suppl 3): S93-6. 
25. Arata T, Kamitani M, Miyai T, Ito M. Antiseptic effects at injection sites. Dermatology 1997; 195: 107-10.

26. Selvaggi G, Monstrey S, Van Landuyt K, Hamdi M, Blondeel P. The role of iodine in antisepsis and wound management: a reappraisal. Acta Chir Belg 2003; 103: 241-7.

27. Infusion Nurses Society. Infusion Nursing Standards of Practice. J Infus Nurs 2006; 29(Suppl 1): S1-92.

28. Birnbach DJ, Meadows W, Stein DJ, Murray O, Thys DM, Sordillo EM. Comparison of povidone iodine and DuraPrep, an iodophor-inisopropyl alcohol solution, for skin disinfection prior to epidural catheter insertion in Parturients. Anesthesiology 2003; 98: 164-9.

29. Kinirons B, Mimoz O, Lafendi L, Naas T, Meunier JF, Nordmann P. Chlorhexidine versus povidone iodine in preventing colonization of continuous epidural catheters in children. Anesthesiology 2001; 94: 239-44. 